\title{
Application of Aloe vera gel instead of silicon dioxide as organic dielectric material in microelectronics
}

\author{
Sardar Masud Rana ${ }^{2}$, Rashed Al Amin ${ }^{1 *}$, Md. AnZAn-UZ-Zaman ${ }^{2}$, SAMioul Hasan $^{2}$ \\ Talukder $^{1}$, Md. Nasrul Haque Mia ${ }^{2}$, Shahzadi Tayyaba $^{3}$, Mahbubul HoQ $^{2}$ \\ ${ }^{1}$ Department of EEE, University of Dhaka (Mymensingh Engineering College), Dhaka, Bangladesh \\ ${ }^{2}$ Institute of Electronics, Atomic Energy Research Establishment, Dhaka, Bangladesh \\ ${ }^{3}$ The University of Lahore, Pakistan
}

\begin{abstract}
Organic materials are now being used in a wide range of microelectronic applications in parallel with inorganic materials, because of their superior properties, environmental safety, and low cost. This paper describes the characterization of Aloe vera gel (AVG), a new organic dielectric material. The surface morphology, spatial distribution of elements, and structural characteristics of an AVG layer were examined using scanning electron microscopy, energy-dispersive X-ray spectroscopy (EDX), and X-ray diffraction (XRD), respectively. The resistance of the AVG layer, determined using a four-probe station, was $640 \Omega$. EDX showed that the elements contained in the layer were carbon, oxygen, aluminum, silicon, calcium, potassium, and copper. The XRD results suggested that the sample primarily consisted of bornite $\left(\mathrm{Cu}_{5} \mathrm{FeS}_{4}\right)$, geerite $\left(\mathrm{Cu}_{8} \mathrm{~S}_{5}\right)$, sal ammoniac $\left(\mathrm{NH}_{4} \mathrm{Cl}\right)$, and carobbite $(\mathrm{KF})$.
\end{abstract}

Keywords: Aloe vera; organic dielectric material; four-probe station; SEM; EDX; XRD

(C) Wroclaw University of Technology.

\section{Introduction}

Organic dielectric materials are a new type of material with structures based on organic materials, i.e. dielectric polymers or small organic molecules deposited on flexible substrates. Organic dielectric materials have the same properties as inorganic dielectric materials but are environmentally safe and readily available. Organic materials have been used in memory devices [1], organic thin-film transistors [2], gas sensors [3], organic solar cells [4], and organic light-emitting devices [5].

Silicon dioxide is used in semiconductors, wire insulation, active gate electrodes in metal oxide semiconductor devices, and fiber optic cables. Silicon dioxide has both advantages and disadvantages. Silicon irritates skin and eyes during contact; it can affect the immune system, and cause lung cancer and mycobacterial infections [6]. Inhalation

*E-mail: rashedoni.eee@gmail.com of silicon dioxide irritates lungs and mucus membranes.

Because of these disadvantages, new organic materials with properties similar to those of silicon dioxide, but which are environmentally safe, need to be developed as alternatives. Most organic dielectrics are based on synthetic polymeric materials. Some natural organic dielectric materials, e.g. chicken albumen [7], fresh leaves of Ficus benghalensis and Gossypium hirsutum [8], maize leaves [9], and apple, banana, carrot, cucumber, grape, orange, and potato tissues, have been reported [10].

In this paper, a new natural organic dielectric material, namely Aloe vera gel (AVG), is described. The software analysis of AVG as a dielectric material in microelectronics instead of silicon dioxide has previously been reported [11]. This study mainly deals with the characterization of thin layers of AVG. The dielectric properties were investigated on a structure obtained by evaporating a thin layer of aluminum on a wafer, 
followed by deposition of a thin layer of AVG. The electrical characteristics of the gel layer were determined using a four-probe station. The gel properties were also examined using scanning electron microscopy (SEM), energy-dispersive X-ray spectroscopy (EDX), and X-ray diffraction (XRD). The results show that AVG layers can be used as the dielectric layer in microelectronic devices.

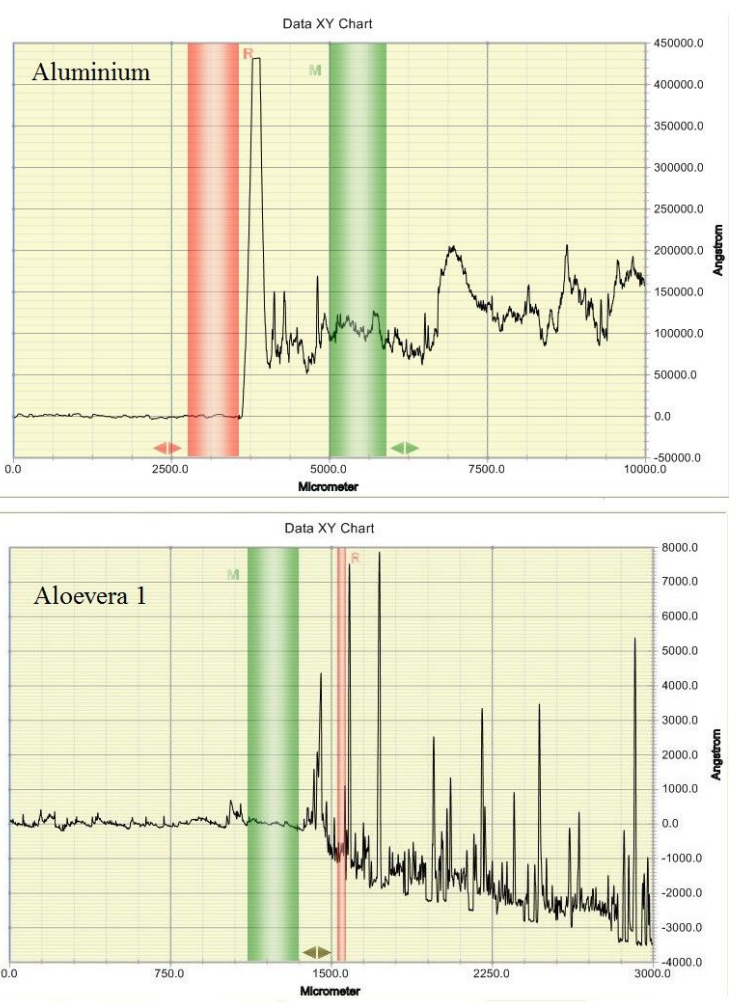

Fig. 1. Dektak analysis of (a) aluminum layer and (b) AVG layer (Aloevera 1).

\section{Materials and methods}

Silicon n-type and p-type wafers were cleaned using detergent and deionized (DI) water. Thorough cleaning was achieved by defect removal using sodium hydroxide $(10 \mathrm{~mL})$ in DI water $(100 \mathrm{~mL})$, and a hydrophobic process using hydrofluoric acid $(1 \mathrm{~mL})$ in DI water $(50 \mathrm{~mL})$. Aluminum was evaporated onto the wafers using a thermal evaporator (Min-coater, Tectra, Germany), at an air pressure of $2.13 \times 10^{-3} \mathrm{~Pa}$. The AVG was obtained from Aloe vera leaves. The AVG was filtered through filter paper, and deposited on the aluminum layers. The gel-coated wafers were heated using a rapid thermal processor (As one-100, France), at $50{ }^{\circ} \mathrm{C}$ for $30 \mathrm{~min}$. The samples were dried at room temperature in a particlecontrolled clean room for $48 \mathrm{~h}$. The thicknesses of the aluminum and AVG layers were determined using a stylus surface profilometer (Dektak 150, USA). The thickness of the aluminum layer was $9720 \mathrm{~nm}$ and that of the gel layers in two samples, Aloevera 1 and Aloevera 2, were 33.2 and $31.1 \mathrm{~nm}$, respectively. The analysis for Aloevera 1 is shown in Fig. 1.

The surface morphologies were examined using SEM (S50QI, AMETEK, USA). The elemental distributions at the central region of each sample were determined using EDX (S50QI, AMETEK, USA), at an accelerating energy of $40 \mathrm{keV}$. The structural characteristics were investigated using XRD (PW 3040, Philips, the Netherlands), at $40 \mathrm{kV}, 30 \mathrm{~mA}$, and a 0.6-s scan-step time at room temperature.

\section{Results and discussion}

\subsection{Four-probe station analysis}

The electrical characteristics of the AVG layer were investigated, using a four-probe station (D-01561, Cascade Microtech, Germany), by passing a current through two outer probes and measuring the voltage across the inner probes to measure the substrate resistivity. The resistances of the aluminum layers evaporated onto the wafers were measured for two samples (Aloevera 1 and Aloevera 2). The resistances were measured again after drying the AVG layers deposited on the wafers. The resistances of the aluminum layers were $2 \Omega$ and those of Aloevera 1 and Aloevera 2 were $2.5 \Omega$. After deposition of the AVG layers on the aluminum layer, the resistances of Aloevera 1 and Aloevera 2 increased to 640 and $621 \Omega$, respectively.

The four-probe station results suggest that the resistance of the AVG layer is very close to those of other dielectric materials, i.e. AVG has good dielectric properties. 


\subsection{SEM and EDX analyses}

The SEM micrographs in Fig. 2 clearly show that the Aloe vera layer consists of organic fibers and particles with irregular and crushed shapes, and pores of size of 4000 to $400 \mu \mathrm{m}$.
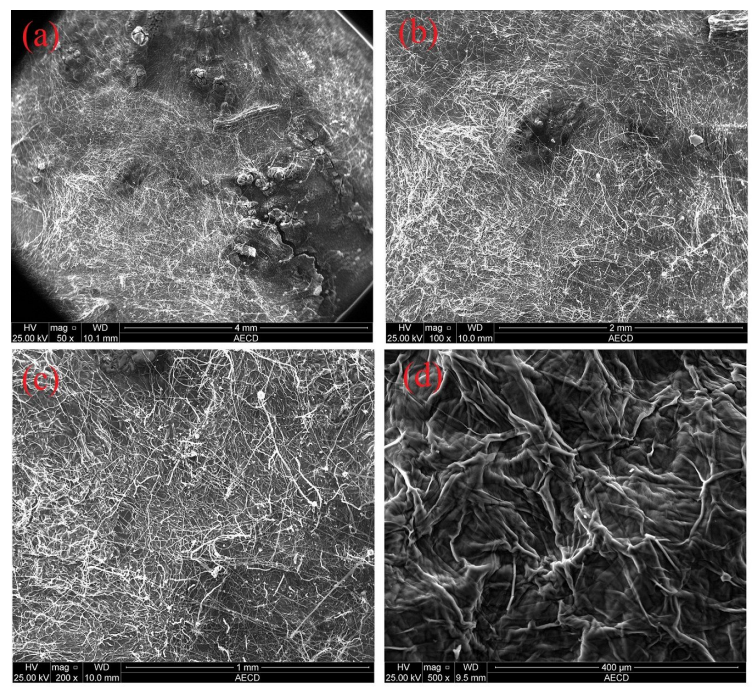

Fig. 2. SEM images of AVG layer at different magnifications.

Table 1. EDX results for Aloevera 1 and Aloevera 2.

\begin{tabular}{cccccc}
\hline \multicolumn{3}{c}{ Aloevera 1 } & \multicolumn{3}{c}{ Aloevera 2 } \\
\hline Element & wt.\% & at.\% & Element & wt.\% & at.\% \\
\hline \hline C K & 33.12 & 46.44 & C K & 35.36 & 47.41 \\
O K & 31.83 & 33.51 & O K & 42.86 & 43.14 \\
Al K & 11.81 & 07.12 & Al K & 00.27 & 00.16 \\
Si K & 02.93 & 01.76 & Si K & 00.72 & 00.41 \\
P K & 00.71 & 00.39 & P K & 03.58 & 01.86 \\
K K & 04.95 & 02.13 & K K & 03.41 & 01.41 \\
Ca K & 03.64 & 01.53 & Ca K & 06.95 & 02.79 \\
Others & 11.40 & 07.12 & Others & 06.85 & 2.81 \\
\hline
\end{tabular}

EDX analysis showed that the AVG layers contained carbon, oxygen, aluminum, silicon, calcium, potassium, copper, and other elements. Table 1 summarizes the weight percentages of detected materials in the Aloe vera gels.

Because of the high weight percentages of oxygen in the gels, it can be assumed that aluminum, calcium, potassium, and silicon are present in the oxide form; other elements may form various compounds. The EDX results for Aloevera 1 and Aloevera 2 are shown in Fig. 3 and Fig. 4, respectively.

\subsection{XRD analysis}

XRD was performed using a Philips PW-3040 $\mathrm{X}$-ray diffractometer, with a $\mathrm{CuK} \alpha$ radiation source $(\lambda=1.54178 \AA)$; a scanning rate of $0.02^{\circ}$ s was used to record the pattern in the $2 \theta$ range of $10^{\circ}$ to $80^{\circ}$. The major diffraction peaks for Aloevera 1 were at $33.03^{\circ}, 68.90^{\circ}$, and $69.21^{\circ}$, corresponding to interplanar distances of $2.71,1.36$, and $1.35 \AA$, respectively. The major diffraction peaks for Aloevera 2 were at $38.55^{\circ}, 44.83^{\circ}, 47.50^{\circ}, 65.16^{\circ}$, and $68.98^{\circ}$, corresponding to interplanar distances of $2.33,2.02,1.91,1.43$, and $1.36 \AA$, respectively. The XRD patterns are shown in Fig. 5 and Fig. 6, and the identified components are listed in Table 2.

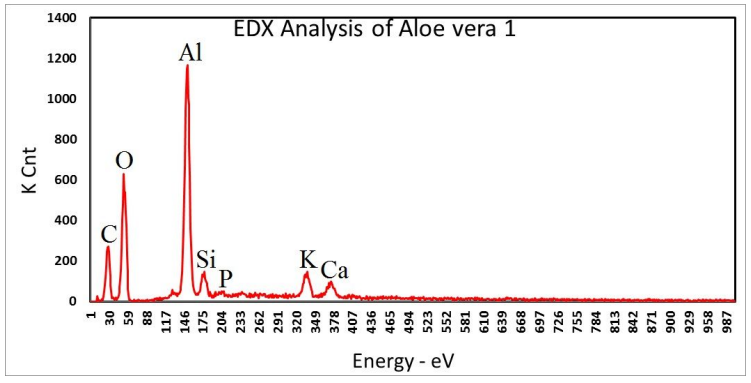

Fig. 3. EDX results for Aloevera 1 gel layer.

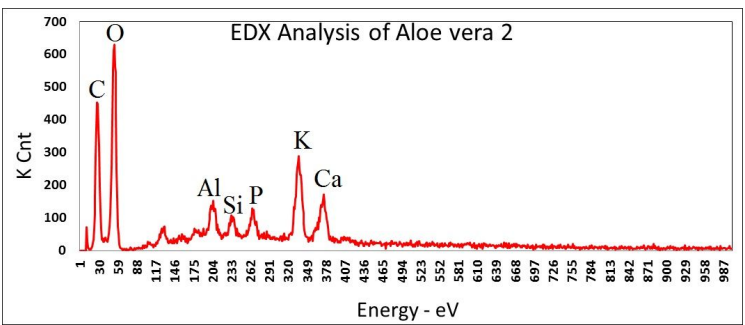

Fig. 4. EDX results for Aloevera 2 gel layer.

Rosenholtz et al. [12] reported that the dielectric constant of bornite $\left(\mathrm{Cu}_{5} \mathrm{FeS}_{4}\right)$ was larger than 81, and Sukyte et al. [13] reported that the sheet electrical resistance of geerite $\left(\mathrm{Cu}_{8} \mathrm{~S}_{5}\right)$ layers varied from $2.0 \mathrm{k} \Omega$ to $1.2 \times 10^{3} \mathrm{k} \Omega$, suggesting its dielectric properties. However, the amounts of these 


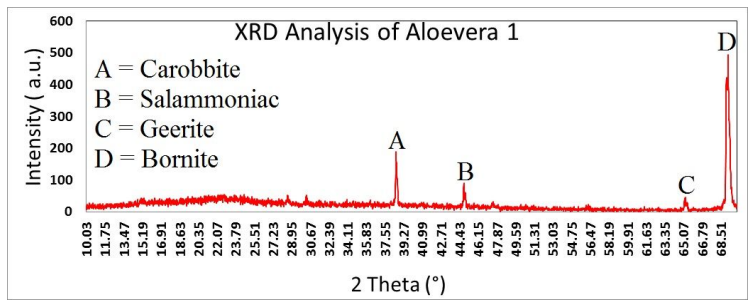

Fig. 5. XRD pattern of Aloevera 1 gel layer.

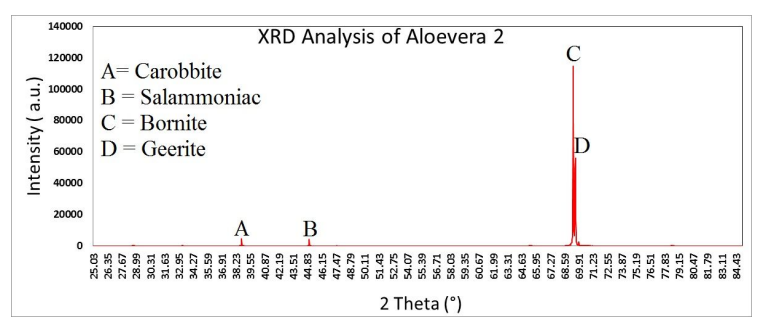

Fig. 6. XRD pattern of Aloevera 2 gel layer.

Table 2. XRD results for AVG layers.

\begin{tabular}{cccc}
\hline Ref. Code & Score & Compound & Chemical formula \\
\hline \hline $01-089-3618$ & 09 & Carobbite & $\mathrm{K} \mathrm{F}$ \\
$00-007-0007$ & 11 & Salammoniac & $\mathrm{NH}_{4} \mathrm{Cl}$ \\
$01-073-1667$ & 83 & Bornite & $\mathrm{Cu}_{5} \mathrm{FeS}_{4}$ \\
$00-033-0491$ & 27 & Geerite & $\mathrm{Cu}_{8} \mathrm{~S}_{5}$ \\
\hline
\end{tabular}

compounds in the AVG were small, therefore, the AVG layer showed good dielectric properties.

The EDX and XRD results revealed the chemical characteristics of the AVG which accurately reflected its dielectric properties. In addition, the gel electrical resistance was determined using the four-probe analysis. The dielectric constants of AVG and silicon dioxide are 3.39 and 3.9, respectively [14]. The dielectric properties of AVG are similar to those of silicon dioxide but the gel has advantages over silicon dioxide. AVG is, therefore, a potential candidate for use in dielectric layers in organic electronic devices. These experimental data provide new information on the dielectric properties of AVG, which may be useful in microelectronic applications.

\section{Conclusions}

This work investigated the surface morphology, spatial distribution of elements, chemical composition, and resistance of an organic dielectric material. The results showed that the AVG contained small amounts of inorganic minerals, endowing it with dielectric properties. This study showed that AVG can be used as a natural organic dielectric material, instead of silicon dioxide, in the fabrication of microelectronic devices.

As in the cases of some other organic materials, an AVG layer has high surface roughness and inhomogeneity. Future work will involve reducing the surface roughness and investigating the performances of microelectronic devices containing an AVG layer instead of silicon dioxide.

\section{References}

[1] Ouyang J., Chu C.W., Tseng R.J., Prakash A., YANG Y., P. IEEE, 93 (2005), 1287.

[2] Bettinger C.J., Bao Z., Adv. Mater., 22 (2010), 651.

[3] Regaco M.P., Dirani E.A.T., Fonseca, F.J., AnDRADE DE A.M., $12^{\text {th }}$ Int. Symp. El., 2005, 441.

[4] Puigdollers J., Voz C., Martin I., Orpella A., Vetter M., Alcubilla R., 2005 Spanish Conference on Electron Devices, 2005, 165.

[5] KarZazi Y., J. Mater. Environ. Sci., 5 (2014), 1.

[6] Lenntech website (online), http://www.lenntech. com/periodic/elements/si.htm.

[7] Chang J., Wang C., Huang C., Tsai T., Guo T., WEN T., Adv. Mater, 23 (2011), 4077.

[8] Hashmi R.A., Bano N., Khatoon, Ayub S., Pak. J. Bot., 26 (1994), 467.

[9] Ksenzhek O., Petrova S., Kolodyazhny M., Bulg. J. Plant Physiol., 30 (2004), 61.

[10] Nelson S.O., P. IEEE, 2005, 360.

[11] Amin R.A., Rana S.M., Talukder S.H., IQbal M.S., Zaman M.A.U., HoQ M., J. Appl. Sci., 14 (2014), 3507.

[12] Rosenholtz . L., Smith D.T., J. Miner. Soc. Am., 21 (1936), 115.

[13] Sukyte J., Zalenkiene S., Janickis V., Mater. Sci.+, 16 (2010), 108.

[14] Khor L.Q., Cheong K.Y., J. Mater. Sci.-Mater. El., 24 (2013), 2646. 